\title{
A NEW COPY OF THE ATHENA PARTHENOS.
}

(Plate IX.)

\section{I.}

THE Athena Parthenos of Pheidias is so well known to us from the records of antiquity, and from the works of art which have come down to us more or less inspired by it, that we can safely claim to know at least what the essential features of the statue must have been ; and yet there is, and must always be, in the almost certain impossibility of our recovering any part of the original, a large residuum of uncertainty and conjecture, not only as regards the details, but principally as regards the artistic form of Pheidias' figure. Where knowledge can only be based on deduction from a series of more or less closely connected data, every fresh addition to these data must be welcomed as ever so slight a strengthening of probabilities; and therefore the acquisition of a fresh piece of evidence is important, even though it adds but little to our preconceived ideas.

The statuette shown in the two views on P1. IX. was discovered accidentally at Patras, in the summer of 1896 (so far as we could learn), in the square called the Psilalonia. From the records-unfortunately too scanty-of discoveries made from time to time on this site, ${ }^{*}$ it is clear that it must have been a place of some importance in the ancient town; these remains appear to have been generally discovered by chance, and so far as I know, no regular excavation has yet been made on the spot. Considering that the antiquities of the Roman period, at any rate, lie very close to the surface, it is probable that a good deal of unrecorded

* Cf. Ath. Mitth. 1895, p. 233, architectural remains, including unfluted drums of columns $1.50 \mathrm{~m}$. high by $\mathrm{I} \mathrm{m}$. in circumference; $i$ ibid. p. 376, an ancient well $6 \mathrm{~m}$. deep. 
discovery must have been taking place here for a long time past. In some cases, the denudation of the surface soil by heavy rains has been sufficient to lay bare Roman remains; but it is quite possible that an excavation might reveal, at a lower depth, the remains of the Greek period.

We (Mr. Bosanquet, Mr. Clark and myself) had been attracted to Patras, in November, 1896 , by the announcement in an English paper, of the discovery of a fine mosaic pavement in the Psilalonia. As no account of this mosaic has yet appeared, I may be allowed to make it the subject of a small digression here. It appears that a short time before our visit, a heavy rain had one night washed away a considerable quantity of surface from the square, and revealed the existence of the mosaic; the further clearing and cleaning of the design was due to Mrs. Wood, the wife of the British Consul at Patras, who herself did what was necessary to make this interesting pavement available for study. When we saw it, some rough posts had been driven, partly into and partly round it; and some rails afforded an inadequate barrier against the local street boys and others, whose depredations had unfortunately left only too obvious traces in the destruction of part of the design.

After our departure, Mr. Clark returned to Patras from a short tour in Achaia, with the intention of making a complete coloured rubbing of the mosaic ; but his work was rendered almost impossible by a spell of bad weather, so that he was only able to complete a coloured rubbing of one figure, and a rough sketch of the whole. Mr. Poynter, two months later, tried to make a study of it, but by that time it had been reburied by the authorities.

The pavement covers a rectangular oblong space, $6.60 \mathrm{~m}$. long by $2.50 \mathrm{~m}$. wide : the designs are enclosed within a border of large beadand-reel pattern $.20 \mathrm{~m}$. wide, which is itself enclosed within a double line of white and red tesserae; at each corner of the bead-and-reel is a quatrefoil. Within this, again, is a band of cable pattern, ${ }^{\prime} 2 \mathrm{~m}$. wide, of which the strands are alternately yellow, red, and white, and each pattern is bounded by a line of red inside a line of white tesserae. A similar band of cable pattern divides the mosaic longitudinally into two equal parts, each of which contains a frieze of figures. In the upper frieze, which has suffered the most damage, is a series of figures holding masks, standing in various attitudes conversing, with a large table in the 
centre : some of the figures appear to be musicians, and the one on the extreme right * is a kitharist, wreathed, and apparently beardless, who steps to left with his face turned nearly to front, his right arm extended holding a plectrum, with which he has just struck the chords of a large kithara on his left arm. $t$ He wears a long red chiton barred horizontally with blue, a variegated mantle hanging from his shoulders, and yellow boots. The ground line is black, and the colours employed are green, yellow, purple, black, white, and dark blue, on a white ground.

The subject of this scene appears to be the preparation for a Dionysiac contest, in which music and the drama are represented. The lower scene forms an appropriate pendant: here the different contests of the palaestra are represented by athletes singly or in groups, each contest being separated from the rest by the figure of an athlete bearing a palm branch. This scene has in all twenty-one figures.

The mosaic is fairly careful and spirited in design, and the tesserae of which it is composed are, as a rule, small; in its style it resembles a mosaic found in the German excavations west of the Acropolis, and must be assigned to about the second century A.D. The unusual character of the subject in the upper design makes it highly desirable that a proper publication should be made of it by some one who can devote more time than we were able to give to it.

II.

The Demarcheion of Patras is distinguished by two imposing sarcophagi flanking the doorway, which naturally attract the inquisitive archæologist. On the occasion of our visit, the Demarch himself was away, but an obliging townsman introduced us to a ragged little pile of sculptures which lay forlornly heaped in a corner of the official reception room; presumably the jetsam cast up by chance and the weather at Psilalonia. These included a marble torso of Artemis, apparently of late Greek work, about 2 feet high; the base of a marble group, of which the feet only are preserved, and which has probably

* Of this figure Mr. Clark succeeded in making a full-sized coloured rubbing.

+ For this figure $c f$. the paintings from Cyrene, published in Pacho, Voyage dans Cyr., Pll. XLIX. and L., which offers, perhaps, the best parallel to the composition of the Patras mosaic. 
represented Eros embracing Psyche; and a marble slab with a relief representing a sepulchral banquet of the usual type. These, however, were obviously of small importance compared with the statuette (Pl. IX.) which we were fortunate enough to unearth from its squalid surroundings, and which forms the subject of the present paper.

The marble is Pentelic, and the surface generally is in excellent condition; the left foot in particular, which, from its position, has been well protected, shows that fine gleaming texture, the rávwoıs of Vitruvius, which suggests that the flesh was toned by an artist. Here and there a good deal of hard cement adheres, as if the figure had been built into a wall; in our hasty survey we could discover no traces of colour, but possibly cleaning may disclose some traces.

The head seems to have been made in a separate piece, and to have been firmly fixed in a socket, so firmly, indeed, that the barbarian who coveted it found it necessary, in order to detach it, to break away the greater part of the right shoulder and shoulder blade ;* the same injury probably caused the loss of the right arm ; the left one is wanting from the middle of the biceps; the drapery in the lower folds has suffered minor abrasions, but is generally in good condition; the right foot has also suffered an abrasion which appears to be recent; the upper part, forming about two-thirds, of the snake and shield are wanting; the pedestal is practically complete.

The total height of the figure, so far as it is preserved, is $0.865 \mathrm{~m}$. (about 34 inches), which is made up as follows:-height of base $0.075 \mathrm{~m}$.; base to end of apoptygma, $0.432 \mathrm{~m}$.; thence to centre of girdle, $0.203 \mathrm{~m}$; thence to chin of Gorgoneion, $0.076 \mathrm{~m}$.; thence to angle of $V$ of drapery, $0.076 \mathrm{~m}$. The base is, roughly speaking, $0.38 \mathrm{~m}$. in width, and the same in depth.

In spite of the somewhat heavy catalogue of disasters given above, sufficient of the original still remains, as may be seen from Pl. IX., to show that, in its position and general lines, the figure corresponds exactly with what we know of the Parthenos from other sources. The body stands firmly poised on the right leg, with the left slightly drawn back, and, as a balance to this, the right shoulder is slightly raised, as

* Probably he was anxious to detach, with the head, the whole of the hair and the crest of the helmet, and therefore began his tooling below the point where the end of the crest and the hair met. There is no trace. left of either. 
would be the case if the right hand had held a weight and lay at rest. The left foot rests only on the tread, and behind it, at the back, the drapery is slightly lifted to show the heel; here we see that the sole of the sandal has been thickened to give the foot the necessary tilt forward. In its general lines the drapery follows the same scheme as the other existing replicas, but in none of them is the characteristic effect which we may a priori assume for the Pheidian statue so gracefully suggested as here. The folds, though they are most carefully worked, are free in treatment; and in depth and undercutting they remind us of Schreiber's remark (Athena Parthenos, p. 65), that this characteristic, unsuitable to work in marble, is necessary in the chryselephantine technique, in order to counteract the reflection of the gold, and to produce stronger shadows.

The drapery consists of a chiton, open down the right side, having a long apoptygma which is fastened at the waist with a girdle; as in all the other copies, this girdle consists of two snakes, whose bodies are fastened in a knot, on either side of which the head and neck form a spiral coil, suggesting the disks of a modern buckle; in our copy the snakes' heads are wanting, otherwise the girdle is perfectly preserved. This girdle is placed rather low on the body, and thus the artist is left ample room to trace home the beautiful oblique folds which, starting from the central knot of the girdle, branch out on either side to the breasts, whose form they help to define; this effect is still further aided by the modelling of the aegis, which, instead of being (as in the Varvakeion statuette) a mere shapeless slab, is delicately adapted to the form beneath it, so that the Gorgoneion clasp falls into its natural position, the hollow between the two breasts.

The V-shaped space between the breasts and the knot of the girdle is filled in our copy with a beautiful and characteristic series of folds; which, sloping alternately from either breast, gradually shorten as they draw near the opposite side, each fold turning up at the lower end for a short distance between two of the opposite folds. This arrangement, which is faintly suggested in the Varvakeion copy and Acropolis torso (Schreiber's I.), is only completely given in the Patras statuettes, and there can be little doubt that it approaches more nearly than any other to the form of the original. How feeble it can be when misunderstood can be seen, for instance, in the Ludovisi Antiochos statue (B), where these folds are collected by a kind of shorthand into 
one crude semi-circle. In the Madrid (C) and Capitoline (E) torsoes, there is one fold here which looks like a reminiscence of the true arrangement, but in all the other copies one can see that the artist must have had in view a scheme similar to that of our copy, and which is found in the vase-paintings of the end of the fifth century.*

In the Patras statuette there are above the girdle, branching out each side, three large folds, which taper upward to the breasts, where they are lost; at their broadest width, that is to say, immediately above the girdle, they are hollowed-fluted, as it were-by the pressure of the girdle, for a short distance inwards; and this effect is carried out where they continue below the girdle. This characteristic effect, $\uparrow$ which assists the eye in following the folds, is partially reproduced in one or other of nearly all the replicas, but in most of them its intention is entirely missed, and in none of them is it completely carried through; the Acropolis torso (I), an extremely perfunctory copy, does, indeed, reproduce the details after a fashion, but with an absolute lack of refinement or understanding.

The movement of the left leg, which has left so marked an effect upon the folds of the lower part of the chiton, does not, in any of the copies hitherto known, convey itself also to any part of the apoptygma ; and yet one would expect that the shifting of the position of thigh and hip, consequent upon this movement, ought to make itself felt at least in the loose part of the apoptygma below the girdle. In most copies the general impression left on the eye by this part of the dress is that of a formal regular series of folds with no particular individuality to distinguish one from another. This remark particularly applies to the Minerve au Collier $(F)$ and the Pighianus replica $(G)$. In the Borghese torso $(\mathrm{H})$, and even in the Acropolis torso $(\mathrm{I})$, one sees traces of a break in the regularity of the folds on the left thigh, which, however, remains unexplained till we see, in the Patras copy, what was intended. Here the action of the thigh has suppressed two folds, leaving a suggestion of the modelling of the form beneath : immediately under the girdle these two folds join each other in an angle; and one feels that if the leg dropped back they would again separate into two

\footnotetext{
* The same system is shown also in the folds of the chest of the Demeter (F) of the East Pediment.

$+C f$. the torso of $\mathrm{Nyx}$ in the East Pediment.
} 
vertical folds. This scheme not only creates a pleasing variety in the otherwise monotonous ordering of the apoptygma, but, by carrying upward the suggestion of the action of the left leg, supplies the necessary continuity between apoptygma and chiton, which on the left side would otherwise be wanting.

In the lower part of the chiton of our copy the general scheme of folds is very much what we have already in the better replicas; between the two legs is one broad fold, forming, as it were, a kind of central pivot for the whole draped figure; two heavy folds descend vertically on the right foot, separated from each other and from the last-mentioned fold by deep under-cutting; the two deep shadows thus created are almost, but not quite, continuous with two upon the apoptygma, descending from the girdle-knot. The question has been raised, in connection with the other copies, as to how these folds terminated on the right foot; in some ( $\mathrm{B}$ and $\mathrm{H}$ for instance) the folds terminate without apparent reason before reaching the foot; in $F$ they lie bunched up on the instep. In our copy the folds begin to curve outward before reaching the foot, where they end apparently in a slightly wavy line; unfortunately, the foot is injured here, but there seems no doubt of the scheme being this, which is suggested in the Varvakeion copy, and appears in other works, as, for instance, the Caryatides of the Erechtheion.*

In our copy all the important folds are moulded with a slight longitudinal depression in the centre; while this does not unduly increase the number of vertical lines, it greatly reduces the hardness of effect which is produced, for instance, by the reproduction of the Ludovisi Antiochos statue (B) : it attains the effect of a middle course, in fact, between that statue and the Minerve au Collier ( $F$ ), with its bewildering multiplicity of folds, and there can be no doubt that here again we are nearest to the original.

The aegis of the Patras statuette, as compared with that of all the other known copies, is extremely narrow, so that the lower edge leaves nearly the whole of the breast uncovered; this detail is additional evidence of the early date of our copy; it is hardly necessary to point out the artistic advantage gained by an aegis so treated; the concave edges on either side of the Gorgoneion, each formed of a single snake,

* Cf. also the standing figure in the Metope of the North Side, Br. Mus. Cat., 322. 
are so adapted as to follow exactly, and so to define, the beautiful upper outline of the breasts. It can scarcely be a mere coincidence that precisely the same feature is found on the torso of Athene from the West Pediment of the Parthenon;* there, also, a scollop of the narrow aegis (which was possibly an invention of Pheidias) sweeps in a single curve around the upper surface of the right breast. The device is so simple and obvious as to seem of little moment; its real artistic importance is only seen when one compares the other replicas with ours; in most of these the aegis is palpably too wide; in the Wolkonsky statue (Schreiber's D) and the Borghese torso $(\mathrm{H})$ there is some indication that the artist may have had before him an original of this type; but there is not one in which the beauty reflected by this part of the Patras statuette is so much as suggested.

In no part of the statuette is there so much variation among the copies as in the aegis. The best copies undoubtedly retain decided traces of the older form. Previously to the Parthenos it would appear that fashion ordained that each of the scollops of the edge should terminate in the forepart of a snake, forming a conventional fringe to the aegis. The later copies are characterised by an absolute freedom in this respect, when the object seems to be to endue each individual snake with as lifelike a character as possible. In our copy, the scollops terminate each in a spiral, formed of the forepart of a snake; the body passes along the edge to the next point, where it is clipped by the forepart of the next snake, but its tail lies flat on the surface of the aegis, and the tails thus form the suggestion of a conventional pattern.

The narrow form of aegis, which coincides with the form found in vase paintings subsequent to the Parthenon, and which is undoubtedly the form used by Pheidias for the Parthenos, is found only in our copy, and in the Capitoline torso $(\mathrm{E})$, which, though only roughly executed, is charmingly simple in treatment. In all the other copies, a much wider form of aegis is found, the result being that the Gorgoneion, which necessarily forms the centre, though relatively increased in size, is widely separated from the lower edge with its row of snakes : in order

* Lange, in Ath. Mitth. vi., p. 86, notices what is wanting in the Varvakeion, but seems to regard the Pediment figure as a later stage. " $Z$ war ist noch nicht der Schritt zur rein decorativen schärpenartigen Aegis geschehen, den Phidias selbst an der Athena des westl. Parthenongiebels nachmals gethan hat." 
to fill the empty space and to connect the edges clasped by the Gorgoneion with the lower snake-fringed edge, the artists of $B, F, G$ add the tails of two snakes which proceed out of the crown of the Gorgoneion and branch out one on either side of it; the foreparts of these snakes are not shown: in $\mathrm{H}$, even a step further is taken, and a similar pair of snakes issues from the ears of the Gorgoneion. Possibly these were suggested by the fact that in the original (as in our copy) the tails of the two central snakes of the lower edge turn up, one on each side of the Gorgoneion. Traces of these tails are to be found in most copies, especially in $B$ and $F$. In $D$ and $E$, they are reduced in scale out of all proportion, in order to get them into the confined space left by the exaggerated Gorgoneion. The Gorgoneion itself, in our copy, still retains traces of the archaic type, with the wide squat face of horror, the salient cheeks, flat nose, wrinkled forehead, and eyes drawn up to their widest at the inner angle.

The curves of the upper edge of the aegis, sweeping upwards in a single line on either side from Gorgoneion to shoulder, prepare the eye for the $V$-shaped fold, which the edge of the chiton makes at the centre of the neck. At the back, the aegis falls slightly lower than in front, and is simply treated, the scolloped edges of the front being replaced here by straighter and more formal lines; it is possible that the copyist may not have felt it necessary to follow his original so closely in his rendering of the back of his copy; it must, however, be said that in Pl. IX., $b$, full justice is hardly done to this part of the Patras figure; the treatment of the back suggests nothing of carelessness, but rather a broad simplicity of modelling, an effect which may well have been produced by Pheidias' own treatment of this portion of the Parthenos. The lower edge of the aegis at the back corresponds broadly to that of the front; that is to say, we have the coiled snake below each shoulder-blade, and the edge sloping up between them to a central angle $\Lambda$ at the spine; from this point a single fold of the dress runs vertically to the girdle, with lateral folds sloping symmetrically inwards from the direction of the shoulders.

The surface of the aegis in our copy is left plain ; possibly the scales were indicated in colour, which has perished. The edges are formed by the actual bodies of the snakes, which are so arranged that the head of each one links round the tail of the next; the tails lie in the aegis itself, 
and the heads of two, now broken away, have been so arranged as to form a kind of pendant below the Gorgoneion. The form of the coils of these snakes, and also of the corresponding snake at the back of the figure, suggest that within them, in the original, may have stood pins which fastened the aegis in position. This fact may prove to be interesting in connection with the question as to the facilities which existed in the original for detaching the gold. It is generally accepted that the removable bullion of the statue (forming a reserve fund of the Athenian treasury) was fashioned into the drapery of the goddess.* But before the drapery could be removed, it was clearly necessary that the aegis should be first taken off, which, from its greater thickness, must have represented a large weight of gold. It is natural to suppose that some mechanical contrivance rendered this an easy matter; when once the Gorgoneion was removed, the two flaps would be separated; and it would be necessary for security to fasten each down with a nail. If, then, the front and back portions met in a joint on the shoulders like those of a cuirass, but here, of course, invisible, there would be no difficulty in removing the aegis in three pieces; the back portion, being nearly flat, would be, if necessary, detached in one piece, sliding down beneath the hair and crest of the helmet. No better place could be found for concealing the necessary pins than within the spiral coils of the snakes' necks. $\dagger$

If we allow, then, that the aegis was probably fastened down with nails, it becomes interesting to note that on the back of the aegis of the Varvakeion copy there are two small but well-marked projections, one on each shoulder-blade, which suggest nothing so much as nails or pins. If these may be taken as representing some detail existing in the original, it may be that they formed some additional fastening which had become necessary by the time when the Varvakeion copy was made.

On the left shoulder are preserved the remains of two double tresses of hair, such as we know from the other examples must have existed in the original, hanging forward over the aegis.

* The simple arrangement of the Doric chiton, open down the entire right side, and without the addition of under chiton or himation, would doubtless greatly facilitate the task of detaching the drapery from the figure.

+ Probably these would be the $\eta^{x} \lambda$ ot $\chi \rho v \sigma o i$ of the inscriptions, e.g. C. I. A. ii., 660, 9 . 
III.

On the left-hand side of the Parthenos stood her shield, resting on its edge, and supported by her left hand; and between the shield and the figure the Erichthonios snake. In the Varvakeion statuette these details are complete, and may probably be regarded as fairly accurate rendering of the original, as they were almost exactly reproduced in the Patras copy, so far as we can judge from the surviving portion. Here the snake is probably rearing up its head at about half the height of the shield; its body is folded in a complex series of twisting coils, somewhat in the form of a double figure of eight, and its tail, resting on the ground, passes round at the back nearly as far as the right side of the figure, with an effect which peculiarly enhances the suggestion of intimate association between the Parthenos and her oikovpos ö $\phi$ s.

In the Varvakeion figure the coils of the serpent are much more open, and the head of the snake comes nearly as high as the top of the shield. In our copy the body of the snake is unhappily wanting from the point at which the neck begins to strike upwards, but the coils are much more compressed, and the head of the animal can hardly have come much higher than the centre of the shield. This complex treatment of the coils necessarily presents much more difficulty to the artist, especially when working (as the copyist at any rate did) in the confined space between shield and figure; thus we obtain a further point of evidence in favour of the superiority of the Patras statuette. It may well have been the skill shown by Pheidias in surmounting the technical difficulties just referred to which make Pliny* select it as one of the points specially admired by connoisseurs . . periti mirantur et serpentem ...

The question as to the height of the snake's head is important in its bearing on that of the decoration of the interior of the shield. The sole direct allusion in ancient literature to that decoration is the statement of Pliny, that on the concave part Pheidias caelavit deorum et

* N.H. xxxvi., I9. We are not told in what material the snake was wrought. Since, whoever, Pliny specially mentions the Sphinx as the solitary exception (in bronze), we may presume that the snake was in the chryselephantine technique; a fact which would further enhance the difficult of its construction. 
gigantum dimicationes. It has been suggested* with great probability that the composition was not in relief, but painted, and Pliny's further reference (xxxv. 54) to a shield at Athens painted by Pheidias has been adduced as an additional argument for this conclusion.

On the other hand, H. L. Urlichs + finds this view untenable. $\mathrm{He}$ prefers to abide by the strict sense of Pliny's term caelavit as meaning carved in relief, and sets this assertion against the vagueness of traditur, explaining the clipeumque Athenis as one of those shieldshaped votive paintings of which actual examples are known ( $c f$. Paus. V. 10, 4); and relying upon the composition of the sentence, he takes intus and Minervae as referring to Panaenus alone.

As to the use of traditur here, the obvious meaning is that Pliny was conveying some information which he had not himself verified, and of which he did not feel personally sure: there is absolutely no reason why we should saddle it, as Urlichs does, with the further meaning, "dass diese Ueberlieferung sonst nicht beglaubigt ist." And I cannot see why the tradition which knew that a shield at Athens had once been painted by Pheidias, should necessarily also know what that shield was. Nor need we follow Urlichs into the elaborate philological antitheses which lead him to reject this passage as having no bearing on the subject. This matter is really, when all is said and done, of minor importance, because, even if it be proved that Pheidias had once painted a votive shield of small interest, it does not follow that he did not also paint the interior of the Parthenos shield: so that the chief question after all turns on the other Pliny passage (xxxvi. 18 ); on that and on common sense. In this passage it is true that Pliny used the word caelavit of the decoration both on exterior and interior, and on the soleae; and that caelare is ordinarily used of carving in relief; but in a statement of this kind, where the writer is mentioning three cases of decoration, of which the first is sculpture in relief, it is only a very natural looseness of terms to allow the one word to cover the decoration which is not in relief, but painted; not to mention the great probability that Pliny himself may at the moment have forgotten that the interior was painted.

* Originally by Urlichs, Chrestom. Plin. ; cf. Robert, Arch. Märch., p. 24, and FurtwänglerSellers, p. 45.

+ In Wochenschrift für kl. Phil. 1895, p. 548 ; he is followed by Sellers and Jex-Blake, The Elder Pliny's chapters, p. 99 note. 
For that painted it was, I have no doubt; if not, how comes it that none of the copies show reliefs on the interior side? After all, it is a question not so much of word-splitting as of common sense. What Greek artist would have dreamt of arming his patron goddess with so unpractical a weapon as a shield with interior projections such as would render its use impossible? From the universal practice of antiquity, it is clear that, if anything is put on the interior of a shield, it could only be some soft lining which would protect the arm when it was in use, just as we know the Greeks usually lined their helmets and greaves with felt ( $\pi \hat{i} \lambda$ os) or sponge. This lining is frequently shown on shields in vase paintings, and it is probable that wherever we find representations of decoration on the interior of a shield, ${ }^{*}$ such decoration is intended to indicate, not painting or engraving direct on the metal, and still less relief, but the designs either of painting or textile which were usually employed for the decoration of such linings.

It may perhaps be urged that the shield of the Chryselephantine Parthenos was only a hieratic "property," and not necessarily a practical weapon. Apart from the artistic reasons which obviously militate against this view, there is also the statement of Pausanias

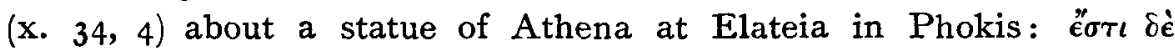

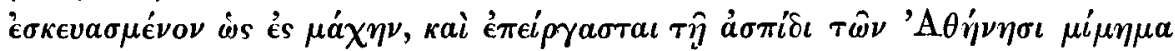

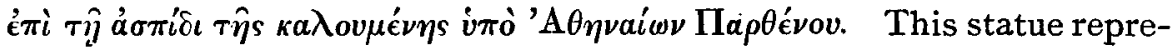
sented the goddess equipped for battle, that is to say, she must at any rate have had a shield copied from that of the Parthenos on her left arm. This is borne out by the coin-type of Elateia (Br. Mus. Cat., Central Greece, pl. iv. 26). Thus it is clear that the shield must have been one which would not look incongruous on the arm of a figure in action.

In asserting the practical impossibility of our finding in Greek art a shield decorated with reliefs on the interior, I may, perhaps, be met with the objection, as Mr. G. F. Hill reminds me, that shields with such decoration are actually found on coins. Thus, on the fourth-century coinage of the Locri Opuntii, a warrior (Ajax) is represented with a shield which has on the interior a snake, a lion, or a gryphon, which appears to be in relief. The snake is shown rising from a single coil in the lower part of the shield, with the head raised nearly to the upper edge. The arm of Ajax is passed through the ochanon and grasps the porpax,

\footnotetext{
* Sec the instances quoted in Furtwängler-Sellers, p. 45, note 4.
} 
and the snake's body passes between it and the shield. If then this snake is in relief, what could be more awkward and unpracticable for the forearm passing over it?

In one instance (B. M. Cat., Central Greece, No. 7) not only does the snake's neck pass under the arm, but the entire coil of the body also passes beneath the broad diametrical band which forms the ochanon. It is therefore, I think, clear that the designs on the shields of this type are not intended to be considered as in relief; they are so represented on the coins, because the method of the coin-artist necessitated rendering all detail in this way. They are probably decoration, painted or woven on the lining of the shield; and in this connection it may be observed that on some of these coins there is shown a puckered edge within the rim of the shield which certainly suggests the edge of a lining.

Just as the design on the exterior of Athene's shield was in principle

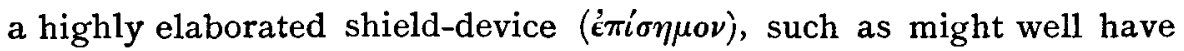
been found on a practical shield of the period; so that of the interior was the imitation of a decorated shield-lining, equally familiar to the spectator; and obviously the only method of rendering this on the chryselephantine shield, short of the insertion of actual leather or textile, would be painting. We know that the cult-statue, in a sense, summed up the motives set forth in the decoration of her shrine: and it may be more than a mere coincidence that the textile decoration chosen for the interior of her shield should be the battle of gods and giants, which was prescribed for the weaving into the peplos annually presented to her.

It is obvious, indeed, that the position of the shield of the Parthenos-nearly edgewise to the spectator, and allowing him to see the interior at an angle never greater than $45^{\circ}$-rendered painting, for its concave surface, much more appropriate than relief. Even so, it has been generally felt that the snake, covering the greater part of the interior as it does in the Varvakeion copy, would be a serious obstacle to any view whatever of the decoration of this part. Schreiber (Athena Parthenos, p. 83) considers that the Varvakeion copy must be unreliable on this point, and that we must suppose the shield of the original as set so much further from the figure as to leave the snake free and the interior surface of the shield clear. 
But the evidence of the Patras copy, as compared with the others, tells in precisely the contrary sense; it is a priori more probable, as I have already suggested, that the copyist would tend to increase, rather than to diminish, the distance between shield and figure, in order to lessen the difficulty of working the snake. Take for instance the Varvakeion copy; here the space between shield and figure is at its widest, but the result is that the left arm would, if extended, hang nearly down to the knee. It is plain that the artist has been led into this want of proportion by his arbitrary widening of the space in question. In the Lenormant copy the arm is in better proportion, but still wrong, and an ugly strut (which can never have existed in the original) attaches it to the hip. On our statuette the left arm, preserved to a point half-way down the biceps, suggests a position much closer to the body (practically that of the Caryatides of the Erechtheion, for instance); and at the level where the hand would come is a rectangular joint, showing that the hand touched here; the direction of the remaining portion of shield, measured upwards, suggests the same point for its junction with the hand.

We are, therefore, brought to this conclusion: that the shield of the Parthenos probably stood close to the figure. If that be so, and the snake practically covered the interior surface of the shield, how was it possible for the Gigantomachia to be seen ? I think the answer lies in the fact that the snake did not, in the original, cover more than the lower half of the shield, as I have shown is suggested by the Patras copy. Judging from the Varvakeion copy, the handles of the shield were arranged on a line drawn horizontally through the centre. If, as I suppose, the snake's head projected outwards on this same level, a natural tectonic division of the shield into two parts would result, of which the lower would be almost wholly covered by the complex coils of the snake, the upper would be left wholly free, and visible by spectators even to a fairly wide angle. That is to say, the decoration would be practically reserved for that half which, in a concave object seen from below, is best adapted to decoration.

We should thus have, for the painted battle of gods and giants, a semicircular space such as would be regarded by an artist of Pheidias' time as peculiarly appropriate to this very subject. The scene would doubtless be handled somewhat as that on the contemporary Athenian vase- 
fragment published in Mon. Ined., ix. 6. The rim of the upper half of the shield would represent the arch of heaven, within which the giants would be shown piling up rocks on a mountain-side.* The figure of Gaia in the vase-picture is placed at the right-hand lower angle, a position which she may well have occupied on the shield, as being thus nearest to the spectator, and, from the point of view of perspective, at the bottom of the design. It is true that on the vase the gods are represented above the arch of heaven; but I think we may regard this as a detail in which the artist would be guided according to the exigencies of the space he had to fill. The vasepainter, having what is practically a rectangular space to fill, finds it convenient to square the semicircle of the heaven in his composition with the figures of the gods. The painter of the shield is forced to bring his gods within the semicircle. That such a scheme was regarded in antiquity as permissible we see for instance from the shield-form relief of the Niobides, in the British Museum, where the figures of Apollo and Artemis are placed on the topmost levels of the mountainside on which the Niobides stand. $\dagger$

The vase-painting just quoted gives us also a further parallel; the interior of a shield carried by one of the giants taking part in the combat is itself decorated with a Gigantomachia, in which the tectonic division of the shield into two equal portions by the handles is actually represented. Here the gods fight in one half, the giants in the other ; but, of course, in this instance, there is not the structural necessity which existed in the case of the Parthenos for leaving one half of the interior of the shield undecorated.

I had written so far when I chanced upon a curious little discovery, which I venture to hope may be regarded as settling the question once for all. I suppose that if an acknowledged copy of the Parthenos shield can be produced, which has the known relief in the exterior and a painted scene on the interior, all reasonable doubt would at once be removed.

* It is evident, from the existing copies, that the scene of the Amazonomachia on the exterior of the shield was laid on a mountain-side (the slope of the Acropolis), and thus the necessary balance would be struck between the two sides.

$+C f$. Furtwängler-Sellers, pp. 44,45 , where the Pheidian character of this relief is justly pointed out. 
It is curious to think that such a copy has been in the British Museum, and well known since 1865 . In publishing the Strangford shield (Brit. Mus. Cat. Sculpture, i. No. 302) in that year," Conze remarked upon the admirable condition of the surface, on which the traces of the original colour are in many parts still quite distinct. While recently examining this monument once more, it occurred to me that if the interior had ever been painted, possibly some traces of the colour might there also still be found ; and such is actually the case ; by merely turning the shield round, any one may see on the interior the undoubted remains of a painted composition.

In the centre of the circle is carved the ochanon, the broad elbow handle of the shield; in the part which is preserved of the semicircle above this the colours are a good deal worn; but enough remains to show that figures have been painted here; the lower semicircle appears to be divided into two sections by a vertical black line from the ochanon to the rim. In the right-hand section (which in the scheme I have suggested would be concealed by the snake) nothing can be made out; but in the left-hand section is a bearded figure standing on a groundwork of rocks, bending forward to right, and lifting in both hands what is apparently a large rock. The hair appears to be shaggy, and the attitude is one very appropriate to a giant in a gigantomachia ; it is almost identical with that of the young giant in the vase painting already quoted (Mon. Ined., ix. 6), who leans forward lifting a rock in front of the helmeted warrior on the left of the scene. I think, therefore, that we may confidently recognise in the composition a rendering of Pliny's deorum et gigantum dimicationes; and may safely disregard in future any objection to a painted interior based on the use of the word caelavit.

This figure is so distinct that one can only marvel that it has hitherto escaped notice. It is about $0^{-15} \mathrm{~m}$. long, that is to say, on exactly the same scale as the figures in relief on the exterior. It is laid in in a deep red outline, which appears to have been filled in with some pigment or pigments which have perished. The same system has been adopted for the rock which the giant is lifting, while the groundwork of rocks on which he stands seems to be washed in in silhouette of a reddish brown. $\dagger$

* Arch.Zeit., I865, p. 33, Pl. 196-7. + I hope to be able shortly to publish a coloured fac-simile. 
So far as it goes, the remains of this painting bear out the suggestions above made for the arrangement of the interior composition of the original shield; viz., that the part covered by the snake would be left unpainted, and that the combat really occupied only the upper semicircle and the part behind the snake's neck.

\section{IV.}

In our statuette, rather more than two-thirds of the shield, with a corresponding portion of the snake, are broken away. But, most fortunately, enough is preserved to show us an important part of the decoration on the exterior (Fig. I). This consists of two nearly com-

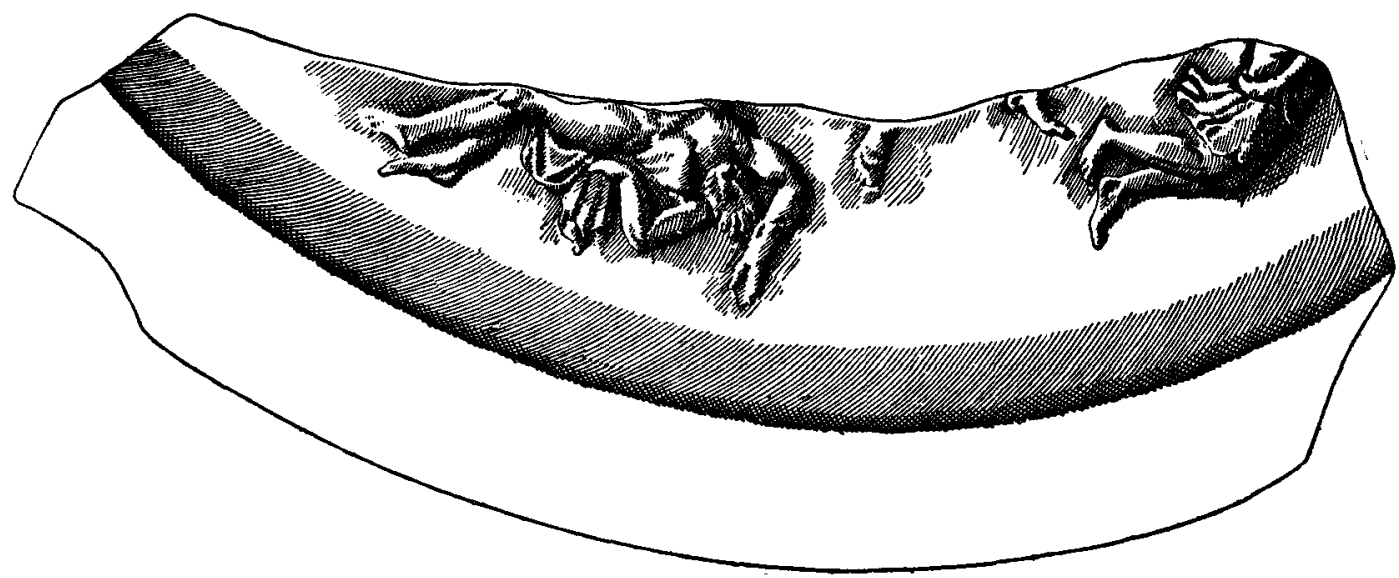

Fig. 1.-Fragment of Shirld of the Patras Statue of Athena Parthenos (Scale, $\frac{1}{2}$ ).

plete figures in relief, and the feet of a third, which evidently belong to a battle of Greeks and Amazons, similar to that which is shown on the Strangford shield, on the Vatican and the Capitoline fragments, and which is very roughly indicated in the shield of the Lenormant statuette.

The accompanying drawing of our fragment, in half scale, is intended rather as a diagram of the figures than as an indication of their artistic quality; which can only be estimated by a comparison of them with the reliefs of the other copies and with analogous reliefs, such as those of the Niobide shield already mentioned. 
The figures are sculptured with great delicacy and freedom, and in this respect are immeasurably superior to those of any of the existing replicas. All the three can be recognised from the corresponding figures in the Strangford and Lenormant copies.* The one on the left of our fragment corresponds to the dead Amazon, who in the Strangford shield lies stretched below the Greek with face concealed, the supposed figure of Pericles. This group clearly was intended to form the lower pivot, as it were, of the composition. In the other replicas the Pericles figure comes immediately below the Gorgoneion, standing over the dead Amazon; and from this group the figures on either side move away. Of the figures in the lower plane, only the four grouped under the Gorgoneion are Greeks; they are confronted with five dead or wounded Amazons. All the remaining figures in the higher plane with one exception appear to be Amazons clambering up the mountain-side. In our copy the surface of the body is unhappily slightly injured; for this reason it is difficult to say whether the artist has designed it for an Amazon, as is undoubtedly the case in the other replicas. At first sight the body appears to be nude, and the fact that it lies on drapery would seem to be against the theory of an Amazon. In the Strangford shield there is no drapery under the figure, which wears a short chiton, leaving the right breast free. In our copy, however, so far as one may judge from a cast, I think I can trace on the left shoulder the line of the chiton, in which case the drapery below the thigh may also be part of the same dress; but the rest of the drapery, hanging from under the left hand in a "swallow-tail" scheme, cannot belong to a chiton. On the whole, the figure of an Amazon is required here, and $I$ think we may take this as an Amazon.

The Strangford figure lies in a somewhat constrained attitude, as if asleep, with both legs bent up at an angle, and by no means suggestive of death; and the left arm is extended, as if she were lying on it. There is, moreover, in the figures around her, a confused tangle of legs which can hardly have existed in the original. These faults are certainly due to the fact that the copyist, in that instance, had adopted a totally disproportionate scale for his figures. With a diameter of only $0.482 \mathrm{~m}$., he has made his figures no less than $0^{\circ} 5 \mathrm{~m}$. long, and the

* The Vatican and Capitoline fragments do not include this part of the design. 
compression of the design thus rendered necessary is seen in every line of the composition.

In our copy, with a diameter* of almost the same size $\left(0^{\circ} 42 \mathrm{~m}.\right)$, the figures are only $0.08 \mathrm{~m}$. long, or very little more than half the size of those on the Strangford shield; and the result is an immense gain in freedom and artistic fitness. The general relation of the figures to the field is, broadly speaking, the same as in the Niobide relief. The dead figure is here shown in what must have been the original pose, with the legs not cramped, but relaxed in the beautiful crossed scheme which Pheidias used, for instance, for some of the figures in the East Frieze (e.g., Michaelis, Parthenon, Nos. 37, 39). The head and right arm hang downwards, as if this part of the figure had fallen forward over the edge of a rock; the left arm hangs loose, but is kept from falling downwards by the weight of the body resting on the hand; by this device the artist conveys the impression that the muscles are relaxed, and at the same time avoids the awkward effect which would be caused by the introduction of a vertical line extending to the edge of the field at this point. The general resemblance of this figure to the dead Niobide on the shield $\dagger$ is at once evident, as also is the parallel use the artist has there made of the lines of drapery composing with the relaxed and flowing lines of the human form. But a still more striking parallel is obtained if we compare the dead figure of a Lapith in a metope of the Parthenon (Br. Mus. Cat. Sculp., 317). This figure repeats almost line for line the forms of the dead figure in our copy, except only that in the more confined space of the metope, the right leg is slightly bent; the body lies within the true plane of the scene, but the head and arms, with the drapery below the body, seem to have hung forward over the border of the design, precisely as is the case with our figure. Furtwängler is of opinion (op. cit., p. 46) that in this class of metope the influence of Pheidias had begun to make itself felt, either directly in his own work upon them, or indirectly through the other artists employed; whichever way we regard it, it is highly probable that the figures on the metope and the shield were closely

* In both cases, the measurements are those of the actual field of the reliefs, that is, the shield minus its rim.

+ Furtwängler-Sellers, p. 44, Fig. 7o. It is also almost exactly repeated in the fine Vienna sarcophagus, Robert, II., xxvii, $68 \mathrm{~A}$. 
related, and that our copy may be considered as very faithful to the original.

In both the Strangford and Lenormant copies of the shield there is shown on the right of the dead Amazon, a group of an Amazon who has fallen on her knees to the right, behind whom is a Greek warrior who has seized her by the hair with his left hand, drawing back his sword in his right to deal her a final stroke. Of these figures our fragment gives the feet of the Greek, and the body, nearly from the shoulders, of the Amazon.* In the Strangford copy the feet of the warrior are placed with a very unfortunate effect, one on the stomach of the dead Amazon, the other on the right leg of his immediate opponent, so that he appears to stride from one to the other with a very uncomfortable foothold. In the Lenormant copy, the right leg of the Greek is nearly in the same position as is indicated in our fragment, but is still not far enough away from the dead Amazon; his left leg has become lost to view behind the falling Amazon. These difficulties are doubtless due to the compression of this part of the scene consequent on the error of scale already mentioned; the same cause is probably responsible for the distortion of the higher planes; thus, the Greek and Amazon who should be fighting immediately above this group, have become, in the miscalculated spacing, entirely separated, so that their respective actions are ridiculous.

Our fragment undoubtedly gives us the figures for the first time in something like their true relative positions. The Amazon is not (as would appear from the Strangford copy) crawling away to the right, but falling or leaping from the hill-side, when she is probably caught by the hair; the movement of her drapery, which is only faintly suggested in the Strangford copy, shows that she is not running, nor yet still; the bent legs, with feet close together, but resting on nothing, must certainly mean that she is falling downwards to the right; a variation of attitude which forms a charming contrast with, instead of tamely repeating, the position of the Amazon immediately above her.

The composition of this group, as a type in art, has a somewhat

* This figure appears to wear the usual high boots, but the condition of the surface does not leave this quite clear. Probably such details were largely here, as in the Strangford shield, indicated in colour. 
special interest. The contrast of the strong, erect, self-contained man, and the fleeing woman on her knees, drawn backward by her long hair, so that all the softer curves of her feminine form are expressed, is the archetype for all classical rendering of combat between the sexes. Created probably originally for the Ajax-Cassandra scene, it became obviously the type par excellence for Greek and Amazon.* Pheidias uses it again in the Parthenon; once more it is a metope which supplies the parallel; with but slight variation the group is identically reproduced on metope No. 14 of the West side (Michaelis, Parthenon, P1. 5, xiv.). From this time forward it becomes almost constant for Greek renderings of the Amazonomachia ; in the Mausoleum frieze it occurs twice (slabs 3,6), and in the Phigaleian frieze no less than five times (slabs $532,534,535,536,538$ ).

\section{V.}

Below the edge of the shield is a support with vertical ends, but of which the upper surface fits into the curve of the shield. A similar support occurs in the Lenormant and Varvakeion copies, $t$ presenting almost exactly the same relative form and size. In copies of these varying dimensions there is no apparent necessity for such a support; nor is it likely that three independent copyists would all have hit upon one of exactly the same relative size and form. It is therefore reasonable to conclude that we have here some feature which existed in the chryselephantine statue of Pheidias. Why was it introduced?

In the first place, a disk resting on its edge, and therefore touching the ground with only a very small portion of its circumference, would present considerable difficulties of reproduction in the chryselephantine technique. Besides, the ordinary Argolic buckler is not so large that when resting on its edge on the ground it would reach to the height of its wearer's hand, unless the wearer stooped towards it. $\neq$ The intro-

* In the Louvre gigantomachia vase (Mon. Grecs, 1875 , Pll. I-2), which is generally admitted to show marked Pheidian influences, it occurs twice ; in each case here it is a deity who seizes a giant by the hair: it had not yet become stereotyped for Greek and Amazon. The same vase offers an interesting parallel in the position of the legs of the wounded Amazon.

+ The Vatican and Capitoline fragments do not include the lower portion; the Strangford shield has probably had the same support, but the entire rim seems to have been tooled away in order to leave a symmetrical edge, which is so mounted that the character of the fracture cannot be seen.

$¥ C f$. for instance, the r.f. krater in the British Museum (Cat. iii., E. 498), where an Athena of the Pheidian type stands with shield resting on its edge on the plinth of the tripod. 
duction of some such support, therefore, was necessary; and introduced, it obviated the necessity of the very difficult task (which would otherwise have been imposed on the artist) of working up the outer surface of the snake's body in a position where it would be very difficult to get at it. Lastly, it was necessary to heighten the shield in order that the spectator might command an uninterrupted view of the paintings on the upper part of the interior. Schneider (op. cit. p. 624) remarks on this necessity, and proposes to open out the space between the snake and the shield; such a plan, however, would scarcely have effected the result required, neither is it warranted by any of the existing copies.

If now we admit that the Parthenos of Pheidias had a support of this character for her shield, it is evident that it must have presented a marked feature in the general design, and as such, it must have been decorated in some way; the more so, as it would have stood nearly on the level of the spectator's eye, and in close juxtaposition to the elaborate reliefs of the shield. That such supports were usually decorated we know from more than one example. Conze, in Philologus, xvii. p. 368 , refers to a statue in the Villa Borghese, representing Athena with shield and snake, in explanation of the word ${ }^{\prime \prime} \nu \theta \epsilon \mu o \nu$, which occurs in three inscriptions. In one of these inscriptions the $\dddot{a} \nu \theta \epsilon \mu \nu$ is described as being $\dot{v} \pi \dot{o} \tau \grave{\eta} \nu$ á $\sigma \pi i \delta a$, and as being fastened in its place with lead; and from the context it is clear that the word must mean just such a support for a shield as we are discussing.

The Villa Borghese statue has the $a^{\prime} \nu \theta \epsilon \mu \nu \nu$ carved in the form of a flower; in a statue found at Civita Lavinia, ${ }^{*}$ the $\ddot{a} \nu \theta \epsilon \mu o \nu$ takes the form of a couching sphinx. This last instance led Lange $\dagger$ to suggest a new reading for the difficult Pliny passage (xxxvi. 19), Sub ipsa cuspide aeream Sphingem. In place of cuspide, he proposes to read aspide, and would assign to the chryselephantine shield an $" \nu \nu \epsilon \mu o \nu$ in the form of a Sphinx. Apart from the improbability that Pliny would have used aspide in a sense only found in the latest Latin, and that he should have used it, moreover, in a passage where the word scutum (already employed), would have done just as well, I think Lange's view is untenable for other reasons; the notion of a Sphinx (or a flower) under a shield would be out of keeping with the artistic ideas of the fifth 
century; and it is fairly certain that if a Sphinx, or any other object in the round had been under the shield of the original, it would have been reproduced in one or other of the copies. Of all the various readings proposed for this much-debated passage, there is not one which seems any more satisfactory than another. As, however, it seems to me extremely unlikely that Pheidias would have introduced more than one Sphinx into his composition, I can only think that Pliny, whether intentionally or not, is alluding here to the Sphinx which we know supported the crest of the helmet.*

Although, therefore, the above instances prove nothing as to the form of the ä $\| \epsilon \mu o \nu$, they certainly increase the probability that it was decorated in some way; its form, indeed, we know already from the combined testimony of all the copies, and what we should expect from its appearance would be a relief or a painted composition.

If now we turn to the passage in Pliny (xxxvi. I 8), we shall find that he devotes one sentence to a description of the decoration of (i) the exterior of the shield, (ii) the interior of the shield, and (iii) the soleae, and adds adeo momenta omnia capacia artis illi fuere. He then goes on to describe (iv) the decoration of the base. As it is generally understood, the sentence beginning adeo seems out of place; for why, if it includes (iii), does it not also include (iv)? If soleae here really means "sandals," the fact that Pheidias decorated the base with dii . . . . $x x$ numero is surely quite as relevant a momentum capax artis as the fact that he decorated the shield and sandals; and it is difficult to see why, to point his remark, Pliny should tack the sandals on to the two parts of the shield.

Is it possible that the whole theory of a decoration of the sandals is based on a misconception? and that the combats of Lapiths and Centaurs were really on the $\ddot{a} \nu \theta \epsilon \mu \nu \nu$ of the shield? In view of the actual existence of a colossal marble foot in Rome $\dagger$ which has a frieze carved on the edge of the sole, I hardly dare venture to make the suggestion; and yet I cannot but feel that it has much in its favour. Of

* The reading which seems to be required is sub ipsa cassidis crista, but the MSS. of course

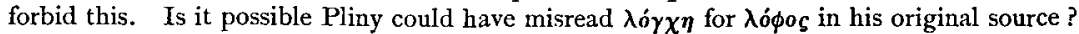

† Figured in Bull. Munic. i., Pl. I, late in style. In the passage of Themistios, or. 25, p. $309 \mathrm{D}$

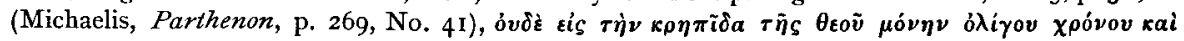
$\pi \hat{\nu} \boldsymbol{x} \pi \rho \circ \sigma \delta \varepsilon \eta \theta \tilde{\eta} \nu a u$, the word $\kappa \rho \eta \pi i c$ probably implies the base or the statue: hence its use in the singular. 
the two spaces offered for decoration, unquestionably the more important is the support of the shield, especially when we remember that the spectator was prevented by a barrier from approaching near the front of the Parthenos, and could scarcely have been able to see reliefs of so small a size as they must have been if they were on the edge of the soles of the sandals.

If, however, the entire sentence of Pliny could be taken as referring to the shield, a great deal of the difficulty would disappear. For this purpose it is necessary to take soleae, in the passage before us, as the equivalent of $\ddot{u} \nu \theta \epsilon \mu \nu \nu$; that such a meaning is possible appears from a passage in Festus, ${ }^{*}$ where the word implies the solid support on which a wattle wall is erected. The passage would then read as follows :"I shall cite those minute details ... . instance her shield; on the convex face he represented the battle of the Amazons, on the concave surface the conflicts of gods and giants, while on the support were the conflicts of Lapiths and Centaurs, so skilful was he in adapting every possible space as a field for his art." Taken in this way, the construction is more natural, and the whole sentence gains in force: the meaning intended being broadly .... " Every portion of the shield, the outside, inside, and support (i.e., momenta omnia) were considered by Pheidias as susceptible of decoration."

Moreover, if we consider the character of the space offered by this $\stackrel{a}{a} \nu \epsilon \epsilon \rho \nu$, which is that of a surface narrowest in the centre and rising outwards on either side-like the two halves of a bisected pediment, joined at the angles-we shall recognise that a battle of Centaurs and Lapiths would be admirably adapted to fill it. The equine body of the Centaur, which at its natural level is lower than the human head, but which, when rearing up, can be made to occupy a much higher level, gives exactly the scale of variations which would be necessary for two sloping fields such as these.

Whether this design was painted or in relief the Pliny passage does not allow us to decide, since the word caelavit, there used for all three subjects, is now shown to cover both painting and relief. Probably, as the support was a merely subsidiary part of the design, and it was

* Ed. Müller, p. 3or. Possibly Pliny was misled by the double meaning of which the word кp $\eta \pi$ is in his original text is susceptible. If he was not familiar with its sense as $=\tilde{a} \nu \theta \varepsilon \mu \nu \nu$, he would naturally translate it as $=$ soleae. 
necessary to mark strongly the contrast between it and the shield with reliefs resting upon it, the Centauromachia was painted; and this is the reason why, in the copies which have come down to us, no trace has yet been found of any design on the support. On the other hand, in more than one of the copies of the Parthenos (Schreiber's B and $\mathrm{H}$ ), traces of the decoration on the sole of the sandal are preserved; and this is clearly shown to be (what, after all, is the most suitable decoration for such a purpose) a mere strap ornament. When we consider that neither of the sandals is completely seen, each being partially cut off by the drapery, the argument in favour of a merely decorative pattern for the soles is strengthened; a figure subject requires a welldefined tectonic space; and a Greek artist would not have committed the error of creating a frieze of which only a part was visible, but the greater part was left to the imagination as running under the drapery of the foot. For an interrupted field like this, it is necessary that the decoration shall be a conventional and self-repeating one; this is one of the first rudiments of the law of applied design.

VI.

It is noticeable that in the Patras copy the base is complete; and here, at least, there can never have been room for a support for the right hand such as exists in the Varvakeion copy. On the other hand, there is no attempt here to indicate any of the decoration which we know existed on the base of the original, and which is indicated in the Pergamene base (Fahrbuch, 1890, p. I 14, fig. 9) and in the Lenormant copy. Consequently, we must conclude that the base of the Patras figure is a mere conventional plinth, and, in the absence of the right arm, we shall not be justified in deducing any conclusion from it as to the original. Moreover, even if there had been a support for the chryselephantine right arm, an olive tree, as Mr. A. S. Murray suggests, or a column, it would not necessarily be reproduced in a copy of this size, for which the mechanical difficulties would not be felt in the same degree. There is no reason, for instance, why the Nike should retain the same relative proportions as in the original; in the PayneKnight bronze copy of the Kanachos Apollo the deer on the hand is reduced to minute proportions; and although the clumsy copyist of 
the Varvakeion Athene finds a support necessary, there is no reason why the skilful artist of the Patras figure should not have been independent of any such device.

In the bare possibility of any light being thrown on the base of the original, every detail deserves to be recorded: it may therefore be worth noting that in both the Varvakeion and Patras copies, the base has a peculiar feature; whereas the right-hand side is square with front and back, the left-hand side is not so; in both copies the left-hand corner of the base at the back seems to be designedly cut away. This may be a mere coincidence, or possibly simply due to the position in which each copy was intended to stand (in a niche or some similarly confined space). In any case the fact is probably not significant, seeing that in neither base has an attempt been made to follow the lines of the original.

VII.

To attempt to assign an exact date to the copy of a great work is in the highest degree difficult, if not impossible. All that one can do is to point out, as I have tried to do, for the Patras copy, the reasons for estimating its position in relation to the original and to other copies. Judged from this standpoint, I have no hesitation in claiming for the Patras copy, that it is at once the earliest in point of date and the most faithful of those which have come down to us. That it is Greek work of a date previous to the Roman period I think no one will deny : and it is even possible that the circumstance of its provenance may help us to a more precise indication of its date.

Pausanias (vii. I 8, 5) says that on the occasion of the invasion of the Gauls the people of Patras crossed over to help the Etolians, but in consequence of the great reverses they sustained and of the poverty by which most of them were oppressed, all but a few of the inhabitants of the town were led to abandon Patras and dispersed throughout the country; and that it was not until the time of Augustus that they were once more collected and the town repopulated. Polybius (xl. 3 ) refers to the same historical event, which must have taken place in 279 B.C.* During this intermediate stage of suspended existence we can hardly

* Frazer, Pausanias iv., p. 143. 
suppose the town to have been entirely deserted; in fact, we have evidence in Polybius and Livy that it was, from its position, a place of call for fleets and armies; but it is evident from the measures taken by Augustus that it had ceased to have any prosperity. It is therefore hardly likely that we can assign our statuette to any date subsequent to 279 B.C.

Now we have in the British Museum a bronze statuette of Marsyas (Cat. Bronzes, No. 269) which was found at Patras," and which, like the one under discussion, is probably also the copy of a masterpiece which existed at Athens. This statuette is generally assigned to the fourth century B.C. And it looks as if the same circumstances which led to the one copy being made, may equally have led to the making and setting up in Patras of the other.

That the worship of Athene was popular in Patras we see from Pausanias (vii. 20), who mentions two sanctuaries and a statue of the goddess there. Beside the temple of Panachæan Athene, within the enclosure of Laphria, whose chryselephantine statue is probably identified on the coins, there was also an "image of Athene in the open air," near the grave of Patreus, within the market-place; and outside the market-place a sanctuary of Athene with a statue of the goddess in ivory and gold; it is conceivable that this last may have been a type borrowed from the statue by Pheidias at Athens.

Cecil Smith.

[It is greatly to be hoped that the Greek Government may be induced to prosecute some further researches on the site where this statuette was found. In November, I896, immediately after our discovery of it, I offered on behalf of the British School to make an excavation with the object of ascertaining whether, as is extremely possible, other fragments of it may not still be in the soil there. Mr. Cavvadias declined the proposal, on the excellent ground, as I understood, that the Government would itself undertake the task; it may be that they have already done so ; but I fear that is not the case.]

* Found in the course of some drainage works by a French Company. See Rayet, Mon. de l'Art, text to $\mathrm{Pl}$. 34 . 
B. S. A., Vol. III. (1896-7), PI.IX.

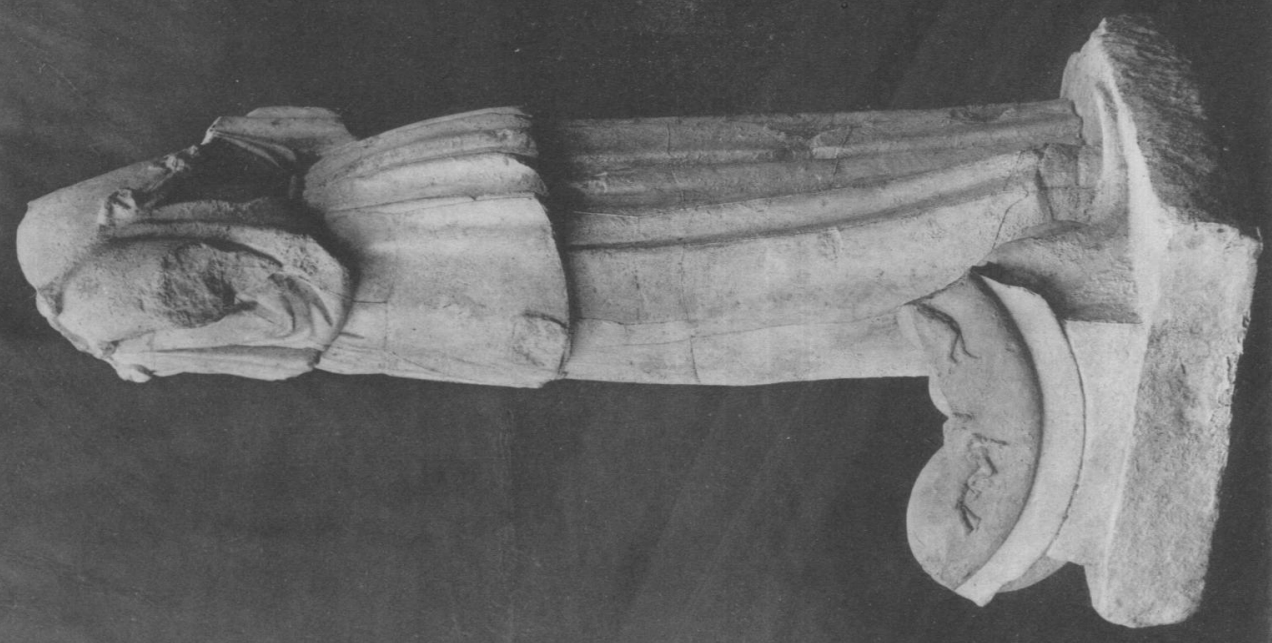

5

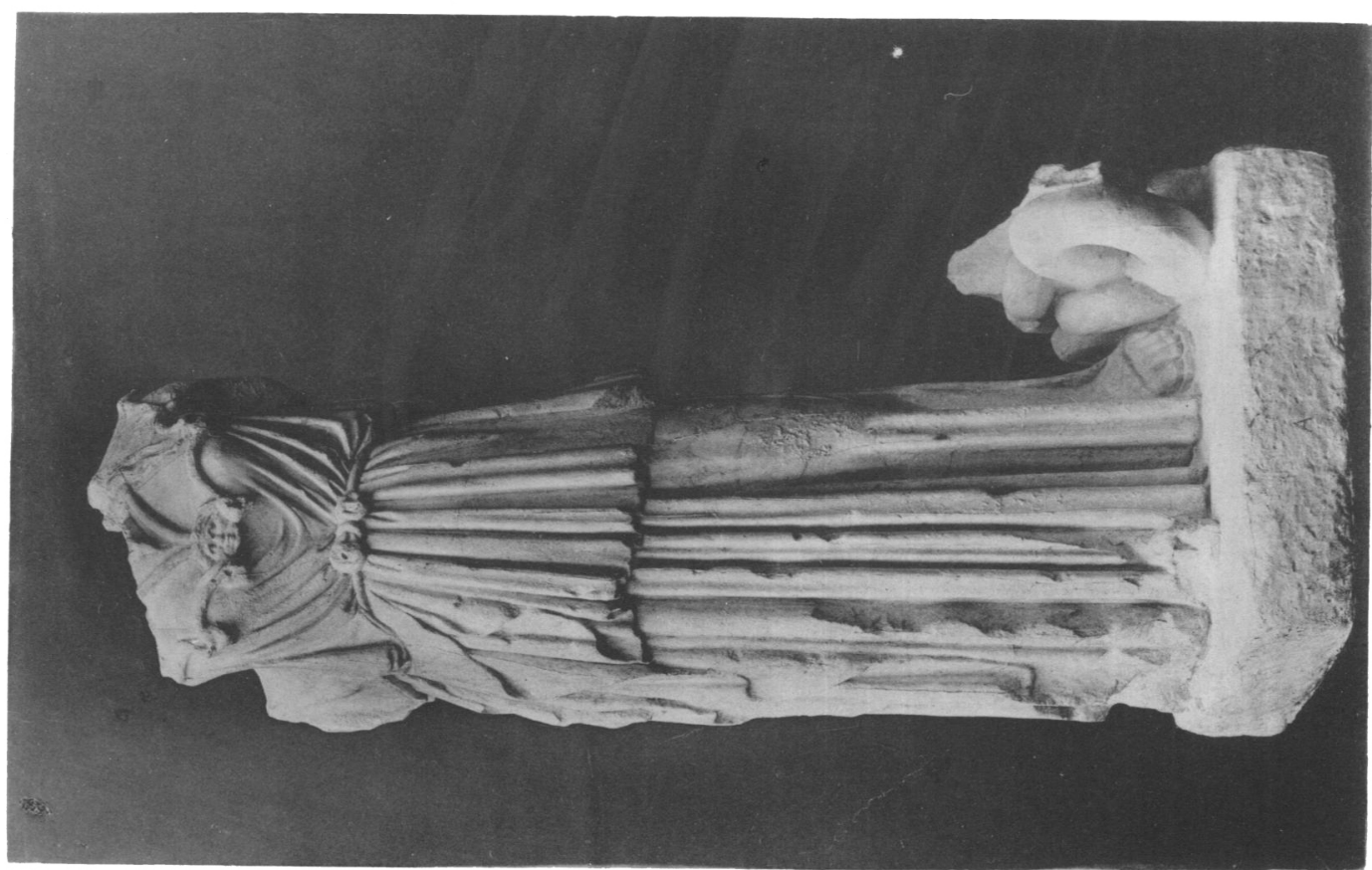

